\title{
The Effect of Proton and Arsenic Concentration on As(III) Removal by Hematite and Kaolin Complexes
}

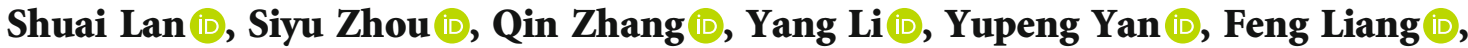 \\ Guanjie Jiang $\mathbb{D}^{\circ}$, and Zhangjie Qin
}

Key Laboratory of Poyang Lake Basin Agricultural Resource and Ecology of Jiangxi Province; College of Land Resource and Environment, Jiangxi Agricultural University, Nanchang 330045, China

Correspondence should be addressed to Zhangjie Qin; qinzhangjie2007@126.com

Received 11 June 2021; Accepted 16 August 2021; Published 17 September 2021

Academic Editor: Haijian Bing

Copyright (C) 2021 Shuai Lan et al. This is an open access article distributed under the Creative Commons Attribution License, which permits unrestricted use, distribution, and reproduction in any medium, provided the original work is properly cited.

\begin{abstract}
With the intensification of human activities, arsenite $(\mathrm{As}(\mathrm{III}))$ pollutant from the soil and ground water has been a threat to human health, and the problem gradually becomes the focus of attention. In this study, the effects of several environment factors on As(III) removal ability of complex minerals are determined through the analysis of mineralogical characteristics of the complex synthesis of hematite and kaolin, using X-ray diffraction, Fourier transform infrared, and specific surface area. In the results, the XRD patterns of hematite and kaolin complexes indicate that the loading covers up some characteristic peaks of minerals in kaolin, which can be that hematite loading decrease the order of structure for some minerals. With increasing Fe content, the hydroxyl sites gradually increase, therefore strengthening the As(III) removal ability of complexes. With increasing the As(III) concentration, the removal ratios of kaolin on As(III) almost keep unchanged and that of complexes show no obvious regularity. However, with the $\mathrm{pH}$ increasing, the removal ratios of all samples keep increasing. Furthermore, the increasing of $\mathrm{As}$ (III) concentration and $\mathrm{pH}$ both improve As(III) removal amount significantly, especially for As(III) concentration. In addition, there is no forming of new mineral through it as observed by XRD. Therefore, hematite loading can promote the As(III) removal on kaolin through adsorption in different environments, which can provide a better method for the remediation of arsenic pollution.
\end{abstract}

\section{Introduction}

Arsenic (As), as a nonmetallic element, is one of the common pollutants and increases the risk of cancer [1]. When a large amount of As is released into the soil and water environments, the ecological environment and human health are threatened extremely [2-4]. For example, 30 million people in Bangladesh were affected by the As pollution in groundwater, in which As concentration is higher than the maximum allowable concentration of drinking water from the World Health Organization [5]. In the soil, most As is inorganic arsenic, existing as in trivalent arsenic (As(III)) and pentavalent arsenic $(\mathrm{As}(\mathrm{V}))$, and $\mathrm{As}(\mathrm{III})$ holds the stronger toxicity and easier migration than $A s(V)$ [6-9]. Therefore, the adsorption is an effective and economic technique for the remediation of the As(III) pollution, which is widely adopted [10-12]. Many studies on the removal of As(III) by single pure phase mineral has been reported, but that by binary or ternary complex needs to be further studied, which can provide a better adsorbent for the remediation of the As(III) pollution.

In the natural soil environment, As is usually adsorbed and/or oxidized by silicate minerals and/or metal oxides, which is the key process to control the effective concentration of As [13-15]. Thus, the soil minerals usually act as a natural adsorbent for different pollutions [16]. Therein, the high content of silicate minerals, which are widely distributed, is characterized by good chemical stability, high cation/anion exchange, and good adsorption ability [17]. Additionally, their surface reactivity shows significant influence on controlling the concentration of contaminants in soil and water. Among them, kaolin clay is the most abundant mineral, which consists of kaolinite with other impurities such as illites, smectites, feldspars, and quartz [18]. 
Kaolin clay with negative charge can adsorb heavy metals with positive charge through ionic exchange with $\mathrm{Na}^{+}$, $\mathrm{Ca}^{2+}, \mathrm{K}^{+}$, and/or $\mathrm{Mg}^{2+}$, which displays a good potential for contaminant removal [19], and acts as a low-cost adsorbent with metal binding capacity [20]. However, kaolin clay holds a relatively weaker adsorption ability for anion, such as arsenate and phosphate. Therefore, the modification of adsorption ability of kaolin clay on anion is still required.

In the natural environment, silicate minerals do not exist alone and usually form complexes with metal oxides and/or organic, leading to the change of the physical-chemical properties of minerals, further the migration and transformation ability of pollutants $[21,22]$. Many studies about the modification of kaolinite have been reported. The modification are mainly performed through intercalation and surface loading compounds, forming complexes and bringing out a better adsorption ability of the minerals on As $[23,24]$. In the tropical or subtropical regions, hematite is a common and important active mineral in soils and can form weakly crystalline iron plaque on other soil minerals, which would greatly improve the adsorption ability of other soil minerals. Furthermore, hematite is proved to be an effective adsorbent to remove arsenate from drink water $[25,26]$. Therefore, in this study, the characteristic of hematite loaded on kaolin clay complexes will be determined, and the interaction between the complexes and As(III) was explored further to explore the important of natural complex minerals. Furthermore, the effects of As(III) concentration and $\mathrm{pH}$ on that interaction are investigated. Especially for $\mathrm{pH}$, it is a very important factor to the adsorption. Many research shows that the adsorptions of minerals on As(III) are decreasing with $\mathrm{pH}$ increasing just like Figure 1 [27-29]. All these results will provide contribution for us to understand the migration and transformation of As(III) in red soil.

\section{Materials and Methods}

2.1. Sample Synthesis. $125 \mathrm{~mL}$ deionized water was heated to $90^{\circ} \mathrm{C}$, and then, $10 \mathrm{~g} \mathrm{Fe}\left(\mathrm{NO}_{3}\right)_{3} \cdot 9 \mathrm{H}_{2} \mathrm{O}$ was added and still completely dissolved. Next, $1 \mathrm{~g}$ or $3 \mathrm{~g}$ kaolin was added, followed by the addition of $75 \mathrm{~mL} \mathrm{KOH}(1 \mathrm{~mol} / \mathrm{L})$ solution to obtain the brown precipitate. Finally, $12.5 \mathrm{~mL}$ of $1 \mathrm{~mol} / \mathrm{L}$ $\mathrm{NaHCO}_{3}$ was added to the above solution and the mixed solution was kept at $90^{\circ} \mathrm{C}$ for $48 \mathrm{~h}$. During this process, it was kept as sealed. The final red precipitate was centrifuged and cleaned with deionized water until the conductivity was less than $20 \mu \mathrm{s} / \mathrm{cm}$, then freeze-dried, and stored in a closed drying environment for standby. The complexes are named as He@kaolin-1 and He@kaolin-3, respectively.

2.2. Characterization of Samples. The obtained samples were characterized by the Bruker D8 Advance powder X-ray diffractometer (XRD) using $\mathrm{Cu} K \alpha$ radiation $(\lambda=0.15418$ $\mathrm{nm}$ ), and the measuring conditions were $40 \mathrm{kV}$ and $40 \mathrm{~mA}$. The specific surface area (SSA) was examined at $110^{\circ} \mathrm{C}$ for $3 \mathrm{~h}$ under vacuum prior by nitrogen adsorptiondesorption isotherms at liquid nitrogen temperatures according to Brunauer-Emmett-Teller (BET) model using

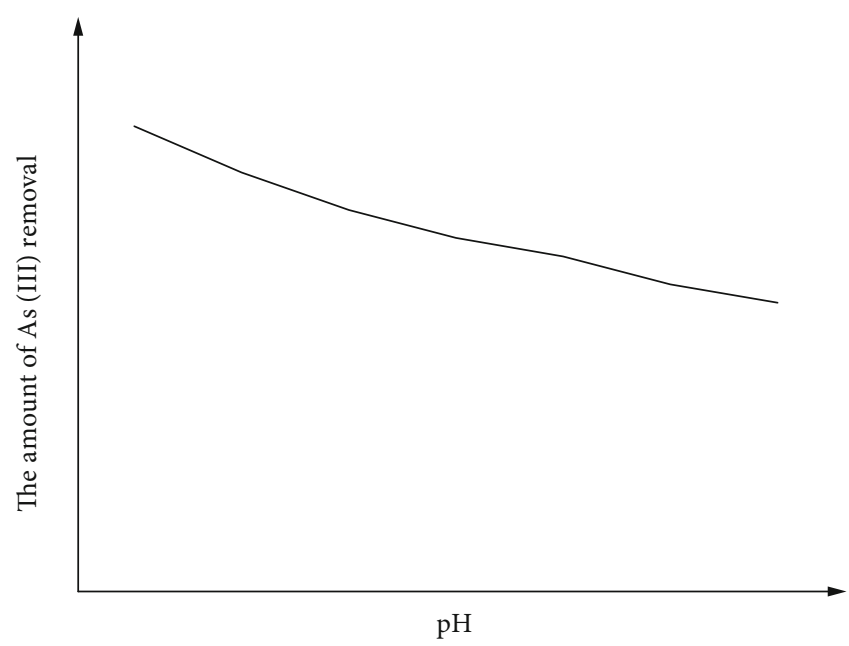

Figure 1: As removal in $\mathrm{pH}$.

Micromeritics ASAP 2020. Fourier transform infrared (FTIR) spectra were acquired using the Bruker VERTEX 70 FTIR spectrometer (64 scans, $4 \mathrm{~cm}^{-1}$ resolution).

2.3. Removal of As(III) by Minerals and Complexes at Different Initial Concentrations. At room temperature, $0.010 \mathrm{~g}$ sample was accurately weighed and added into $50 \mathrm{~mL}$ of $6 \mathrm{mg} / \mathrm{L}, 12 \mathrm{mg} / \mathrm{L}$, and $24 \mathrm{mg} / \mathrm{L} \mathrm{As}$ (III) solution with $0.1 \mathrm{~mol} / \mathrm{L} \mathrm{NaNO}_{3}$. The $\mathrm{pH}$ was kept $6 \pm 0.05$ during the process and magnetic stirring reaction for $300 \mathrm{~min}$. Finally, the suspension was filtered with $0.22 \mu \mathrm{m}$ microporous membrane, and the As(III) concentration was determined by atomic fluorescence spectrometer (AFS-8220, Beijing Jitian Analytical Instrument, China).

2.4. Removal of As(III) by Minerals and Complexes at Different Initial $\mathrm{pH}$. At room temperature, $0.010 \mathrm{~g}$ sample was accurately weighed and added into $50 \mathrm{~mL}$ of $6 \mathrm{mg} / \mathrm{L}$ As(III) solution with $0.1 \mathrm{~mol} / \mathrm{L} \mathrm{NaNO}_{3}$, and the $\mathrm{pH}$ was, respectively, kept $4 \pm 0.05,6 \pm 0.05$, and $8 \pm 0.05$ during the process and magnetic stirring reaction for $300 \mathrm{~min}$. Finally, the suspension was filtered with $0.22 \mu \mathrm{m}$ microporous membrane, and As(III) concentration was determined by Atomic fluorescence spectrometer (AFS-8220, Beijing Jitian Analytical Instrument, China).

\section{Results}

3.1. Analysis of X-Ray Diffraction. The XRD patterns of kaolin and complexes samples were shown in Figure 2. In the XRD pattern of kaolinite, three peaks of diamond labeling represent the presence of kaolinite. There are other minerals in the kaolin along with kaolinite. However, in the XRD pattern of He@kaolin-3, the peaks of kaolin are almost disappeared, and some new characteristic peaks are appeared. These peaks were consistent with (012), (104), (110), (113), (024), and (116) crystal planes of hematite in JCPDS card (24-0072) [30, 31]. With increasing the Fe content, the peak intensity of hematite strengthens in the XRD pattern of He@kaolin-1. However, the content of kaolin is lower than 


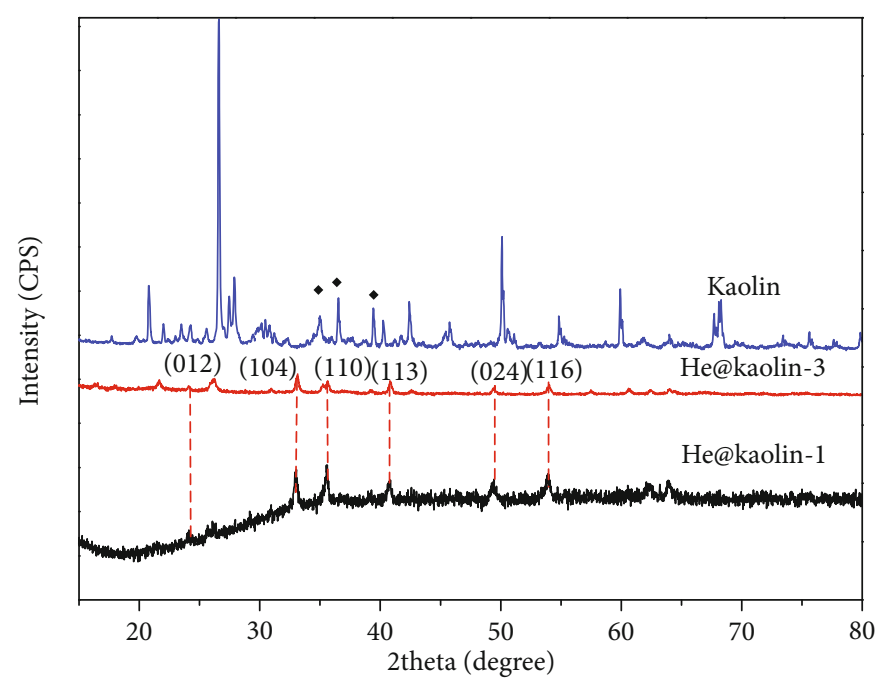

FIGURE 2: XRD patterns of kaolin, He@kaolin-3, and He@kaolin-1.

that of hematite leading to the appearance of characteristic peaks of kaolin in He@kaolin-1 and He@kaolin-3, which will be further proved later.

3.2. Analysis of Fourier Transform Infrared Spectroscopy. The FTIR patterns of kaolin and complexes samples were shown in Figure 3. In the three FTIR patterns, the bands at 3430 and $1630 \mathrm{~cm}^{-1}$ represent the $-\mathrm{OH}$ stretching vibration in adsorbed water molecule [32]. The bands at 1090, 895, and $822 \mathrm{~cm}^{-1}$ represent the vibration of Si-O-Si/Al, Si-OH, and $\mathrm{Al}-\mathrm{OH}$, respectively [24]. Moreover, the bands at 573 and $473 \mathrm{~cm}^{-1}$ in kaolin can be ascribed to $\mathrm{Si}-\mathrm{O}-\mathrm{Al} / \mathrm{Fe}$ and $\mathrm{Si}-\mathrm{O}-$ $\mathrm{Si}$, but that at near wavenumber in He@kaolin-1 and He@kaolin-3 can be ascribed to Fe-O-Fe. Further, the new adsorbed peak at $1345 \mathrm{~cm}^{-1}$ is the vibration of $\mathrm{Fe}-\mathrm{OH}$. Therefore, with $\mathrm{Fe}$ content increasing, the contents of both $\mathrm{H}_{2} \mathrm{O}$ and $-\mathrm{OH}$ increase.

3.3. Analysis of Specific Surface Areas. The SSA of kaolin and complexes samples were measured using BET method, and the adsorption and desorption curves of $\mathrm{N}_{2}$ were shown in Figure 4. The adsorption and desorption curves (Figure 4(a)) and pore size distribution curves (Figure 4(b)) of kaolin and He@kaolin-3 are similar, especially the position and shape size of hysteresis loop. Thus, the corresponding SSAs were 6.48 and $15.87 \mathrm{~cm}^{2} / \mathrm{g}$, and the main pore sizes both range from 20 to $50 \mathrm{~nm}$. But the SSA and main pore size of He@kaolin-1 are $163.43 \mathrm{~cm}^{2} / \mathrm{g}$ and $\sim 5 \mathrm{~nm}$, respectively, which are different from those of the other samples. This phenomenon can be attribution to the important effect of hematite content on the SSA and main pore size of mineral.

3.4. As(III) Removal by Minerals at Different Initial as(III) Concentrations. The removal ratios of As(III) by kaolin, He@kaolin-1, and He@kaolin-3 at different initial As(III) concentrations are shown in Figure 5. For three samples, with Fe content increasing, the removal ratios of As(III) significantly increase at different As(III) concentrations of 6 , 12 , or $24 \mathrm{mg} / \mathrm{L}$. The maximum difference can reach removal

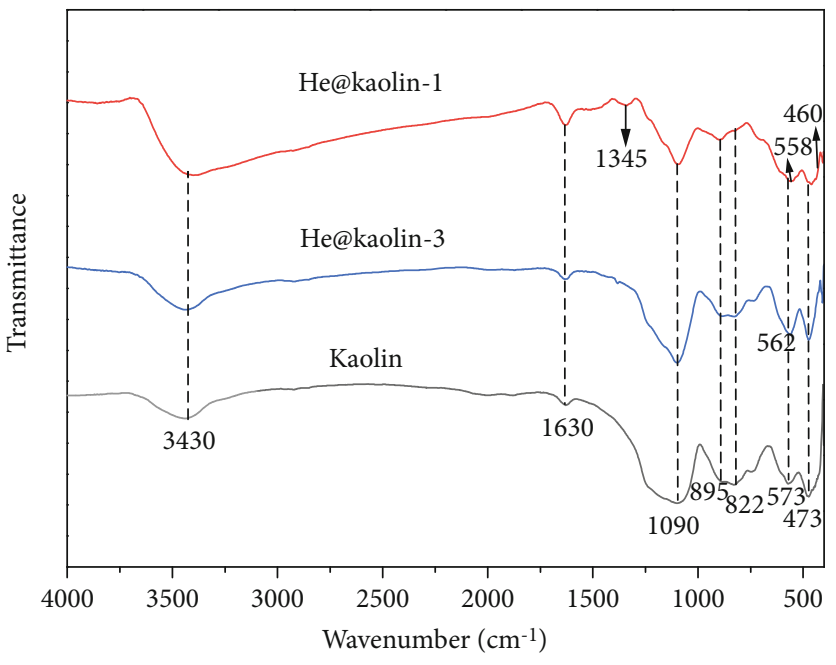

FIGURE 3: FTIR spectra of kaolin, He@kaolin-3, and He@kaolin-1.

ratio of $\sim 50 \%$. However, the removal ratios of As(III) by the same mineral display a minor regular change. For kaolin and He@kaolin-3, the As(III) removal ratios hardly change, while the removal ratios of As(III) on He@kaolin-1 first increase and then decrease. The reasons are that the increasing concentration of $\mathrm{As}(\mathrm{III})$ decreases the removal ratio of As(III) while its adsorption on mineral decrease. In addition, the calculation results showed in Table 1 indicate that the removal amount of As(III) is always increasing significantly with the increasing of Fe content or As(III) concentration.

Furthermore, the adsorption products of kaolin, He@kaolin-1, and He@kaolin-3 at As(III) concentrations of $24 \mathrm{mg} / \mathrm{L}$ were analyzed by XRD in Figure 6 . Through comparison with the XRD patterns of kaolin, He@kaolin-1, and He@kaolin-3 in Figure 2, the characteristic peaks at $21^{\circ}$ and $26^{\circ}$ in kaolin always appeared in He@kaolin-1, He@kaolin-3, and their adsorption products, which is consistent with characteristic peaks of quartz. The other peaks were gradually disappearance or weak after adsorbed As(III), indicating that effect of adsorbed As(III) on structural order 


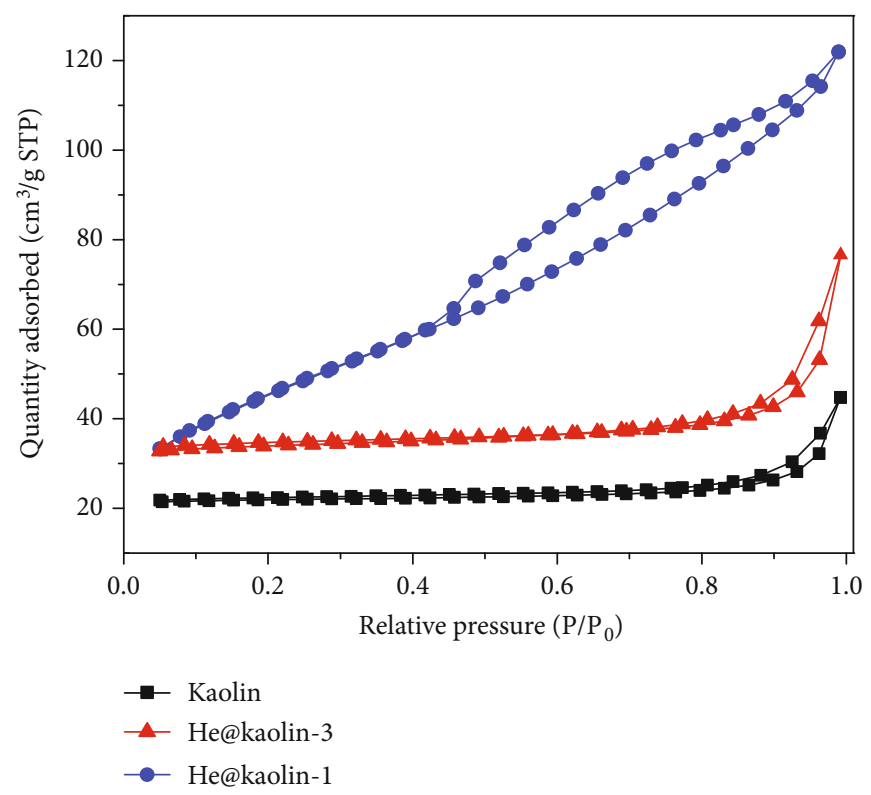

(a)

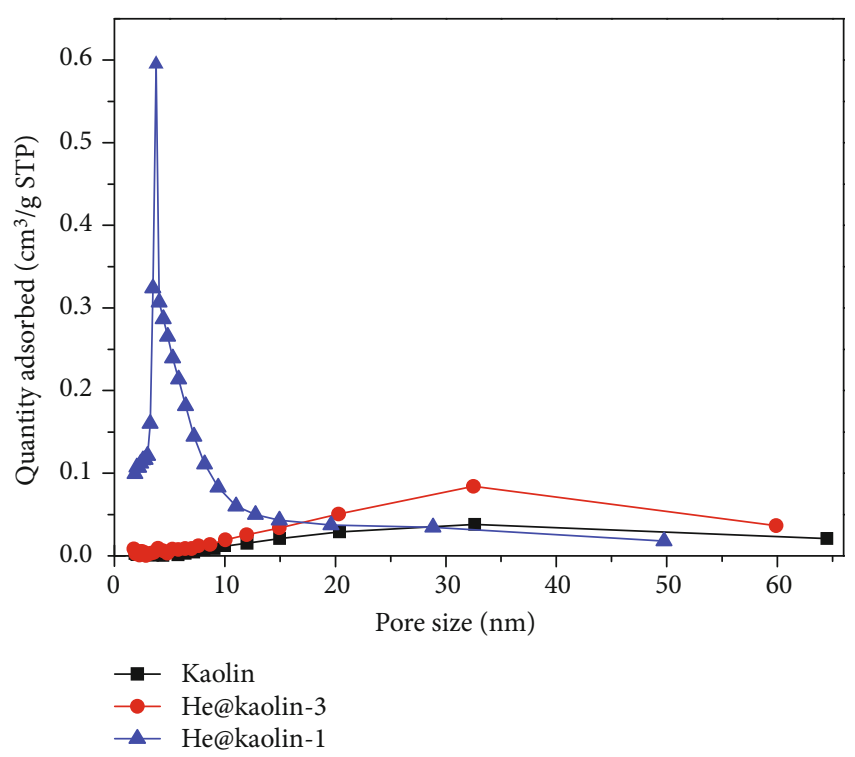

(b)

Figure 4: $\mathrm{N}_{2}$ adsorption-desorption isotherm and pore size distribution of kaolin, He@kaolin-3 and He@kaolin-1.

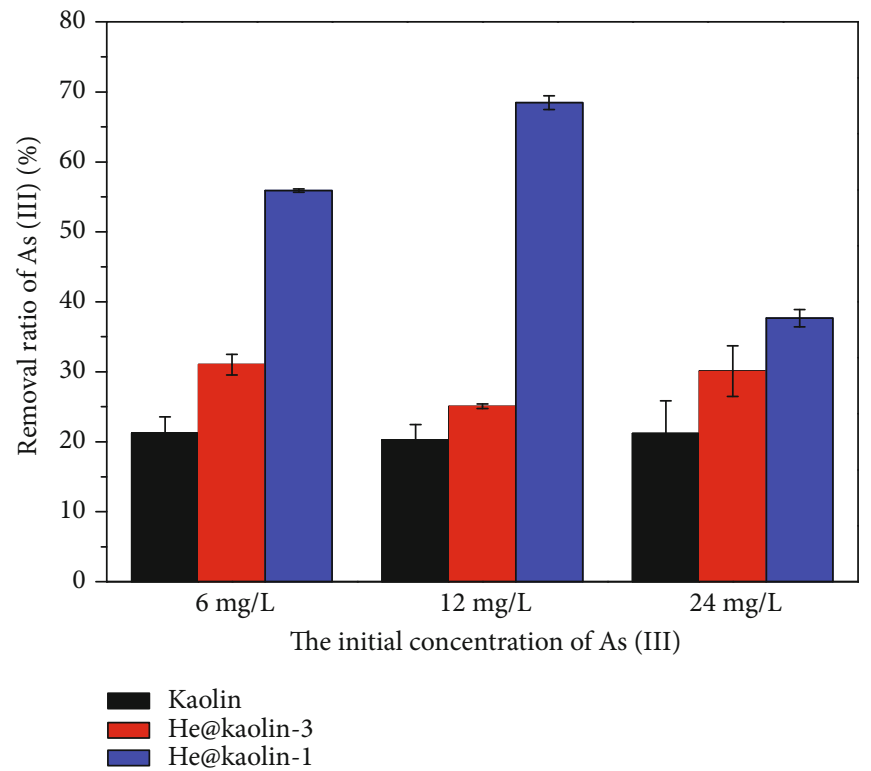

FIGURE 5: Removal ratio of As(III) by kaolin, He@kaolin-1, and He@kaolin-3 at different initial As (III) concentrations (6, 12, and 24 mg/L).

of part minerals in kaolin is strong, like ion adsorption decreasing characteristic peaks of XRD [33, 34]. With increasing the content of $\mathrm{Fe}$, the two characteristic peak intensities of quartz are gradually weak in Figure 2. Meanwhile, As(III) adsorption changed the peak intensity ratio of (104) and (110) in hematite, which is caused by decreasing the peak intensity of (110). The positions of (104) and (110) peaks in hematite for He@kaolin-1 and He@kaolin-3 were obviously shifting to low angle. It indicates that there can be a large amount of As(III) adsorbed on (110) and (104) planes with different influences [35].
TABLE 1: Removal amount of As(III) by kaolin, He@ kaolin-1, and He@ kaolin-3 at different initial As (III) concentrations (6, 12, and $24 \mathrm{mg} / \mathrm{L})$.

\begin{tabular}{lccc}
\hline Samples & Kaolin $(\mathrm{mg} / \mathrm{L})$ & $\begin{array}{c}\text { He@kaolin-3 } \\
(\mathrm{mg} / \mathrm{L})\end{array}$ & $\begin{array}{c}\text { He@kaolin-1 } \\
(\mathrm{mg} / \mathrm{L})\end{array}$ \\
\hline $6 \mathrm{mg} / \mathrm{L}$ & 1.28 & 1.56 & 3.35 \\
$12 \mathrm{mg} / \mathrm{L}$ & 2.43 & 3.01 & 8.22 \\
$24 \mathrm{mg} / \mathrm{L}$ & 5.09 & 7.22 & 9.04 \\
\hline
\end{tabular}




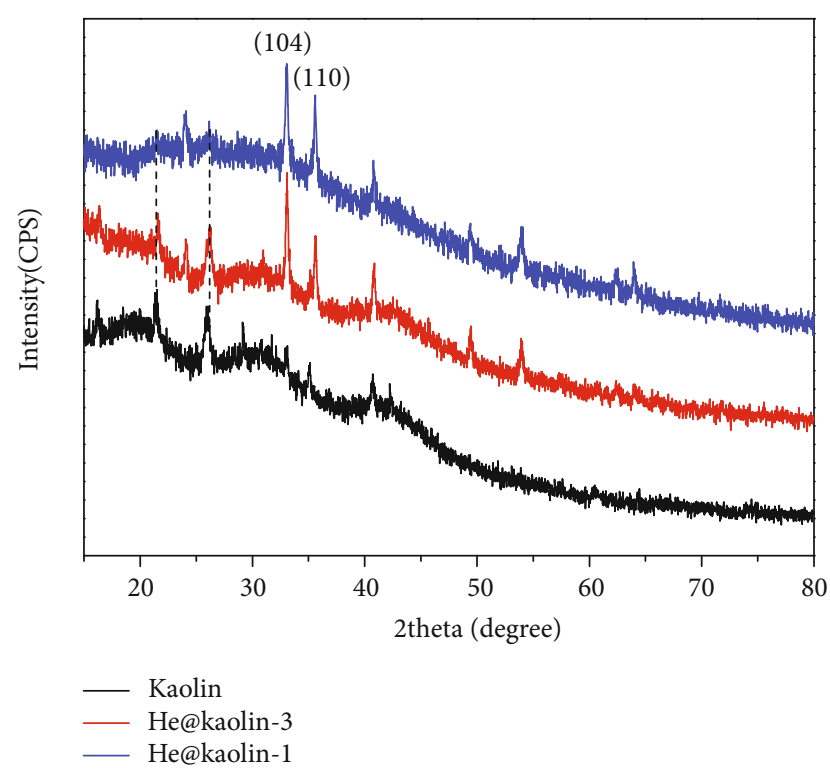

FIGURE 6: XRD patterns of the adsorption products of kaolin, He@kaolin-3, and He@kaolin-1 at 24 mg/L As(III).

Moreover, there were no new mineral appearances in the adsorption products.

3.5. As(III) Removal by Minerals at Different $p H$. Figure 7 shows the results of removal ratio of As(III) by kaolin, He@kaolin-1, and He@kaolin-3 at different pH. With the content of Fe increasing, all removal ratios of As(III) significantly increase at $\mathrm{pH}$ of 4,6 , and 8 . Especially between kaolin and He@kaolin-1, the differences of removal ratio at different $\mathrm{pH}$ can reach $\sim 35 \%$. The removal ratios of $\mathrm{As}(\mathrm{III})$ by the same mineral at $\mathrm{pH}$ of 4,6 , and 8 are also increased except for kaolin at $\mathrm{pH} \mathrm{8,} \mathrm{which} \mathrm{is} \mathrm{not} \mathrm{consistent} \mathrm{with} \mathrm{the}$ results at different concentrations of As(III). Through calculation, the removal amount of As(III) is always significantly increased no matter if the content of $\mathrm{Fe}$ or the $\mathrm{pH}$ in Table 2 is increasing.

Through analysis of the adsorption products of kaolin, He@kaolin-1, and He@kaolin-3 at different pH (Figure 8), the results of XRD showed that, with $\mathrm{pH}$ from 4 to 8 , there is almost no changes for kaolin, and the intensities and positions (104) and (110) peaks in hematite for He@kaolin-1 and He@kaolin-3 were obviously increasing and shifting to low angle. Therefore, arsenite can better enter into the structure of hematite at high $\mathrm{pH}$ and high concentration of As(III), not only adsorption on the surface of hematite. There were no new mineral appearances in the XRD results of products.

\section{Discussions}

4.1. The Effect of Hematite Loading on As(III) Removal. With the ratio of kaolin to hematite decreasing, the characteristic peaks of kaolin are gradually decreasing and disappearance, while that of hematite is increasing. The results indicate that the complex of kaolin and hematite can be synthesized. Through the FTIR analysis, with increasing the content of

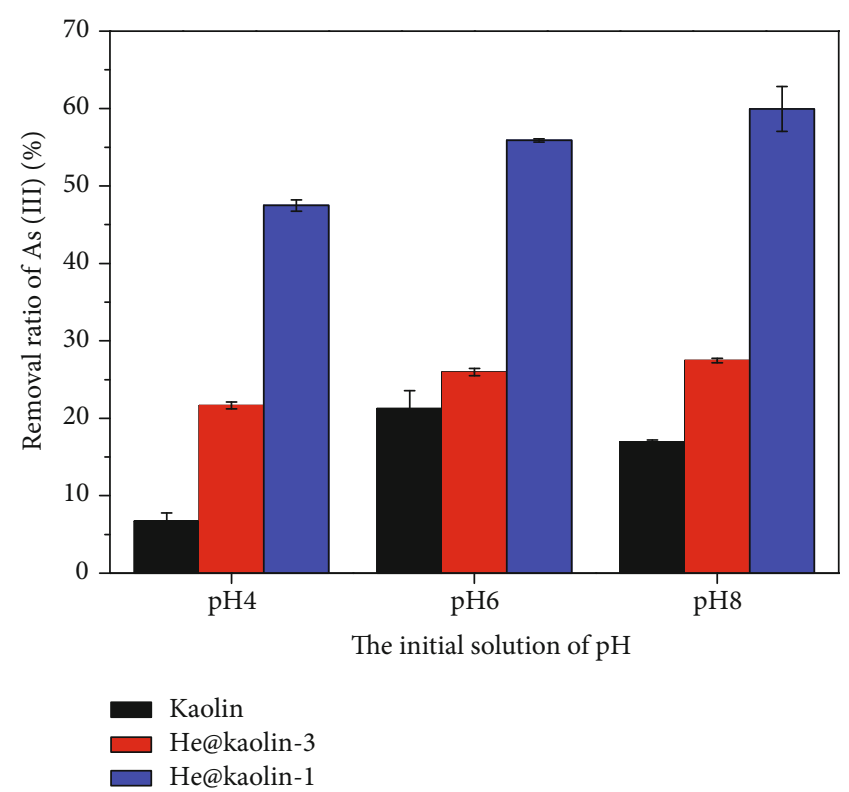

FIGURE 7: Removal ratio of As(III) by kaolin, He@kaolin-1, and He@kaolin-3 at different pH values of 4, 6, and 8 .

TABle 2: Removal amount of As(III) by kaolin, He@kaolin-1, and He@kaolin-3 at different $\mathrm{pH}$ of 4,6 , and 8.

\begin{tabular}{lccc}
\hline Samples & Kaolin $(\mathrm{mg} / \mathrm{L})$ & $\begin{array}{c}\text { He@kaolin-3 } \\
(\mathrm{mg} / \mathrm{L})\end{array}$ & $\begin{array}{c}\text { He@kaolin-1 } \\
(\mathrm{mg} / \mathrm{L})\end{array}$ \\
\hline pH 4 & 0.40 & 1.30 & 2.85 \\
pH 6 & 1.28 & 1.56 & 3.35 \\
pH 8 & 1.02 & 1.65 & 3.60 \\
\hline
\end{tabular}

hematite, the vibration of $\mathrm{Fe}-\mathrm{OH}$ and the $-\mathrm{OH}$ stretching vibration in the adsorbed water molecule are increasing. In addition, the hematite loading can significantly enhance the SSA, which can be mainly from hematite. Therefore, hematite loading on kaolin can increase the active sites and SSA of the complex, leading to decreasing the electrostatic repulsion and promoting the adsorption of As(III) on complex $[36,37]$. For further analysis data, at $\mathrm{pH} 6$, the removal amount of As(III) adds $2.07 \mathrm{mg} / \mathrm{L}$ with Fe content increasing (or kaolin concentration decreasing) from kaolin to He@kaolin-1 at As(III) concentration of $6 \mathrm{mg} / \mathrm{L}$, while that with an addition of $3.81 \mathrm{mg} / \mathrm{L}$ at $\mathrm{As}(\mathrm{III})$ concentration from $6 \mathrm{mg} / \mathrm{L}$ to $24 \mathrm{mg} / \mathrm{L}$ for kaolin. Therefore, the effect of Fe content in mineral on the removal ratio of As(III) is lower than that of As(III) concentration under existing conditions in this study. This is because hematite loaded can reduce the surface negative charge of kaolin, leading to the decrease of the electrostatic repulsion. Furthermore, despite the reaction systems with $\mathrm{As}$ (III) concentration of $24 \mathrm{mg} / \mathrm{L}$, the maximum adsorption amounts of As(III) on minerals are not obtained.

At similar analysis, at a $\mathrm{As}(\mathrm{III})$ concentration of $6 \mathrm{mg} / \mathrm{L}$, the removal amount of As(III) adds $2.45 \mathrm{mg} / \mathrm{L}$ with Fe content increasing (or kaolin concentration decreasing) from kaolin to He@kaolin-1 at $\mathrm{pH}$ 4, while that with an addition of $0.62 \mathrm{mg} / \mathrm{L}$ at $\mathrm{As}(\mathrm{III})$ concentration from $\mathrm{pH} 4$ to $\mathrm{pH} 8$ for kaolin. Therefore, the effect of Fe content in mineral on 

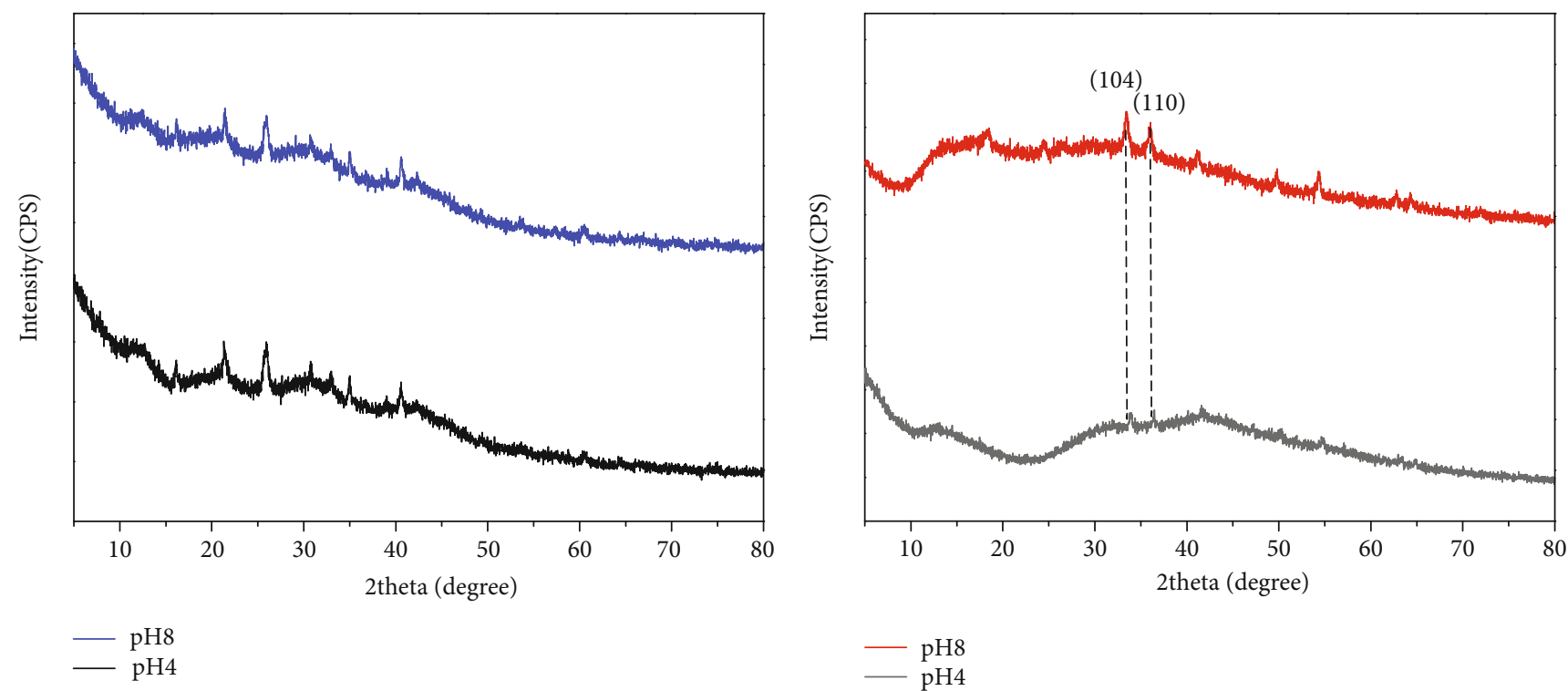

(a)

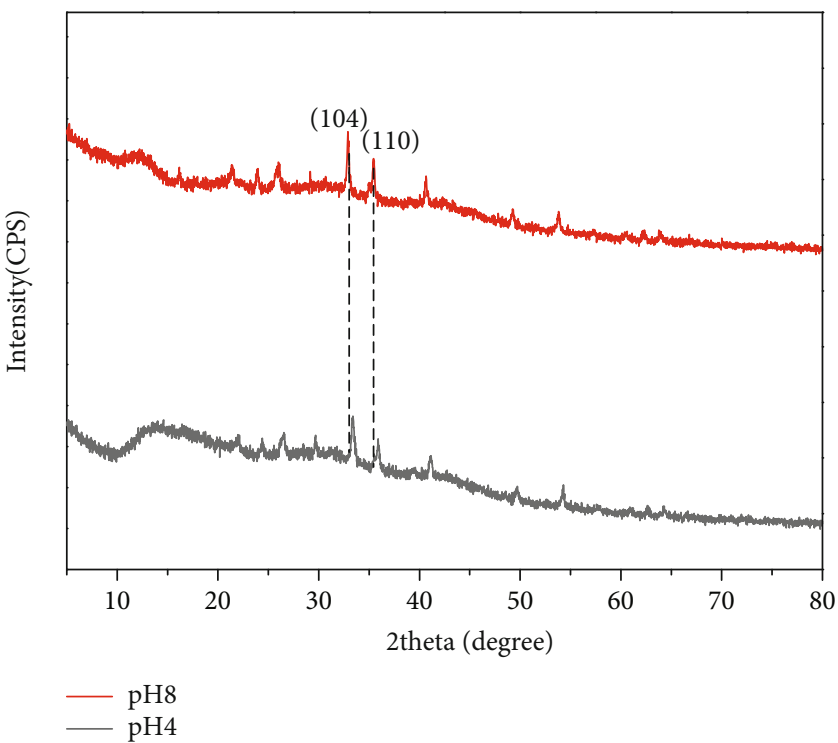

(c)

FIGURE 8: XRD patterns of the adsorption products of kaolin (a), He@kaolin-3 (b), and He@kaolin-1 (c) at pH 4 and 8 with 6 mg/L As(III).

the removal ratio of $\mathrm{As}(\mathrm{III})$ is greater than that of $\mathrm{pH}$. It indicates that hematite loaded have important influence on the removal ratio of As(III) of kaolin. Furthermore, the adsorptions of kaolin and complexes for ions with negative electric charge are usually gradually decreased with increasing $\mathrm{pH}$ [27-29], but the results of the removal ratio of $\mathrm{As}(\mathrm{III})$ is contrary. Because the $\mathrm{PZC}_{\mathrm{pH}}$ of the minerals can be within the $\mathrm{pH}$ range from 4 to 8 , the adsorption of $\mathrm{As}$ (III) species is favoured electrostatically up to the $\mathrm{PZC}_{\mathrm{pH}}$ of the adsorbents; but beyond this point, specific adsorption (ligand exchange) plays an important role [24, 29, 38, 39].

4.2. The Effect of Proton and Arsenic Concentration on As(III) Removal. Based on all above results, the adsorption of kaolin for As(III) is relatively low than that of modified kaolin. And through analysis of the adsorption amount of As(III) at different $\mathrm{pH}$ and concentrations, hematite loading can significantly improve the adsorption of kaolin. Furthermore, through normalization analysis adsorption of kaolin and He@kaolin-1: at As(III) concentration of $6 \mathrm{mg} / \mathrm{L}$ and $24 \mathrm{mg} / \mathrm{L}$, increasing unit concentration can add 0.21 and $0.32 \mathrm{mg} / \mathrm{L} \mathrm{As}$ (III) for kaolin and He@kaolin-1; and at pH 4 and 8 , increasing unit $\mathrm{pH}$ can add 0.16 and $0.19 \mathrm{mg} / \mathrm{L} \mathrm{As}$ (III) for kaolin and He@kaolin-1. Therefore, hematite loading is advantageous to adsorption of As(III) with increasing As(III) concentration, but that adds less adsorption of As(III) with increasing $\mathrm{pH}$. The results indicate that As(III) concentration has more influence on adsorption of As(III) than pH for kaolin and He@kaolin-1, especially for He@kaolin-1. 


\section{Conclusion}

Kaolin clay has a good activity for contaminants in the environment. And a large amount of hematite usually is attached to other minerals' surface leading to increased adsorption ability in the tropical and subtropical regions. Therefore, the complex of hematite loaded on kaolin was synthesized; then, the removal behavior for As(III) is further study. The results show that hematite loading impacted the structure order of part minerals in kaolin and increased the activity sites. In addition, the increase of As(III) concentration and $\mathrm{pH}$ can increase the removal amount of As(III) by kaolin, He@kaolin-3, and He@kaolin-1, especially for the concentration of $\mathrm{As}(\mathrm{III})$, in which increasing Fe content can also further promote the removal amount of As(III). At last, no forming new mineral was observed in the adsorption products. All above results indicate that the migration and effective concentration of arsenic pollutants can be controlled through increasing $\mathrm{pH}$ and/or iron oxide, which can provide reference for remediation of arsenic pollution in the soil or ground water.

\section{Data Availability}

All the basic data that support the results of this study are contained in the article.

\section{Conflicts of Interest}

The authors declare that they have no conflicts of interest.

\section{Acknowledgments}

The research was financially supported by the Youth Fund Project of Jiangxi Provincial Department of Science and Technology (20202BABL215030), Science and Technology project of Education Department of Jiangxi Province (GJJ180231), and National Natural Science Foundation of China (41907018 and 42030709).

\section{References}

[1] M. A. Rahman and C. Hassler, "Is arsenic biotransformation a detoxification mechanism for microorganisms?," Aquatic Toxicology, vol. 146, pp. 212-219, 2014.

[2] E. Smith, R. Naidu, and A. Alston, "Arsenic in the soil environment: a review," Advances in Agronomy, vol. 64, pp. 149-195, 1998.

[3] P. L. Smedley and D. G. Kinniburgh, "A review of the source, behaviour and distribution of arsenic in natural waters," Applied Geochemistry, vol. 17, no. 5, pp. 517-568, 2002.

[4] P. Ravenscroft, H. Brammer, and K. Richards, Arsenic Pollution: A Global Synthesis, Wiley-Blackwell, Chichester, UK, 2009.

[5] D. K. Nordstrom, "Worldwide occurrences of arsenic in ground water," American Association for the Advancement of Science, vol. 296, no. 5576, pp. 2143-2145, 2002.

[6] C. Tournassat, L. Charlet, D. Bosbach, and A. Manceau, "Arsenic(III) oxidation by birnessite and precipitation of man-
ganese(II) arsenate," Environmental Science \& Technology, vol. 36, no. 3, pp. 493-500, 2002.

[7] S. Wang and C. N. Mulligan, "Speciation and surface structure of inorganic arsenic in solid phases: A review," Environment International, vol. 34, no. 6, pp. 867-879, 2008.

[8] S. J. Parikh, B. J. Lafferty, T. G. Meade, and D. L. Sparks, "Evaluating environmental influences on As (III) oxidation kinetics by a poorly crystalline Mn-oxide," Environmental Science \& Technology, vol. 44, no. 10, pp. 3772-3778, 2010.

[9] J. He and L. Charlet, "A review of arsenic presence in China drinking water," Journal of Hydrology, vol. 492, pp. 79-88, 2013.

[10] N. T. Livesey and P. M. Huang, "Adsorption of arsenate by soils and its relation to selected chemical properties and anions," Soil Science, vol. 131, no. 2, pp. 88-94, 1981.

[11] L. Carlson, J. Bigham, U. Schwertmann, A. Kyek, and F. Wagner, "Scavenging of As from acid mine drainage by schwertmannite and ferrihydrite: a comparison with synthetic analogues," Environmental Science \& Technology, vol. 36, no. 8, pp. 1712-1719, 2002.

[12] R. Singh, S. Singh, P. Parihar, V. P. Singh, and S. M. Prasad, "Arsenic contamination, consequences and remediation techniques: A review," Ecotoxicology and Environmental Safety, vol. 112, pp. 247-270, 2015.

[13] K. Banerjee, G. L. Amy, M. Prevost et al., "Kinetic and thermodynamic aspects of adsorption of arsenic onto granular ferric hydroxide (GFH)," Water Research, vol. 42, no. 13, pp. 3371-3378, 2008.

[14] B. E. Hettick, J. E. Cañas-Carrell, A. D. French, and D. M. Klein, "Arsenic: a review of the element's toxicity, plant interactions, and potential methods of remediation," Journal of Agricultural and Food Chemistry, vol. 63, no. 32, pp. 70977107, 2015.

[15] J. W. Stuckey, M. V. Schaefer, S. G. Benner, and S. Fendorf, "Reactivity and speciation of mineral-associated arsenic in seasonal and permanent wetlands of the Mekong Delta," Geochimica et Cosmochimica Acta, vol. 171, pp. 143-155, 2015.

[16] K. G. Bhattacharyya and S. S. Gupta, "Adsorption of chromium (VI) from water by clays," Industrial and Engineering Chemistry Research, vol. 45, pp. 7232-7240, 2006.

[17] M. K. Uddin, "A review on the adsorption of heavy metals by clay minerals, with special focus on the past decade," Chemical Engineering Journal, vol. 308, pp. 438-462, 2017.

[18] C. Belver, M. A. Bañares Muñoz, and M. Vicente, "Chemical activation of a kaolinite under acid and alkaline conditions," Chemistry of Materials, vol. 14, no. 5, pp. 2033-2043, 2002.

[19] L. Deng, Z. Shi, L. Luo et al., "Adsorption of hexavalent chromium onto kaolin clay based adsorbent," Journal of Central South University, vol. 21, no. 10, pp. 3918-3926, 2014.

[20] Y. Zhang, S. Chen, X. Feng, J. Yu, and X. Jiang, "Self-assembly of sponge-like kaolin/chitosan/reduced graphene oxide composite hydrogels for adsorption of Cr(VI) and AYR," Environmental Science and Pollution Research, vol. 26, no. 28, pp. 28898-28908, 2019.

[21] A. Violante, M. Ricciardella, M. Pigna, and R. Capasso, "Effects of organic ligands on the adsorption of trace elements onto metal oxides and organo-mineral complexes," in Biogeochemistry of Trace Elements in the Rhizosphere, pp. 157-182, Elsevier, 2005.

[22] T. Boonfueng, L. Axe, Y. Xu, and T. A. Tyson, "Nickel and lead sequestration in manganese oxide-coated montmorillonite," 
Journal of Colloid and Interface Science, vol. 303, no. 1, pp. 8798, 2006.

[23] R. Mudzielwana, M. W. Gitari, and P. Ndungu, "Uptake of As (V) from groundwater using Fe-Mn oxides modified kaolin clay: physicochemical characterization and adsorption data modeling," Water, vol. 11, no. 6, p. 1245, 2019.

[24] R. Mudzielwana, M. W. Gitari, and P. Ndungu, "Performance evaluation of surfactant modified kaolin clay in As(III) and $\mathrm{As}(\mathrm{V})$ adsorption from groundwater: adsorption kinetics, isotherms and thermodynamics," Heliyon, vol. 5, no. 11, article e02756, 2019.

[25] Y. Jeong, M. Fan, S. Singh, C. L. Chuang, B. Saha, and J. Hans van Leeuwen, "Evaluation of iron oxide and aluminum oxide as potential arsenic(V) adsorbents," Chemical Engineering and Processing, vol. 46, no. 10, pp. 1030-1039, 2007.

[26] J. Gimenez, M. Martinez, J. Depablo, M. Rovira, and L. Duro, "Arsenic sorption onto natural hematite, magnetite, and goethite," Journal of Hazardous Materials, vol. 141, no. 3, pp. 575-580, 2007.

[27] S. Arnamwong, P. Suksabye, and P. Thiravetyan, "Using kaolin in reduction of arsenic in rice grains: effect of different types of kaolin, $\mathrm{pH}$ and arsenic complex," Bulletin of Environmental Contamination and Toxicology, vol. 96, no. 4, pp. 556-561, 2016.

[28] J. O. Eduah, E. K. Nartey, M. K. Abekoe, S. W. Henriksen, and M. N. Andersen, "Mechanism of orthophosphate (PO4-P) adsorption onto different biochars," Environmental Technology \& Innovation, vol. 17, article 100572, 2020.

[29] D. M. Liu, C. Dong, and B. Xu, "Preparation of magnetic kaolin embedded chitosan beads for efficient removal of hexavalent chromium from aqueous solution," Journal of Environmental Chemical Engineering, vol. 9, no. 4, article 105438, 2021.

[30] T. Mansouri, A. Golchin, and M. Neyestani, "The effects of hematite nanoparticles on phytoavailability of arsenic and corn growth in contaminated soils," International Journal of Environmental Science and Technology, vol. 14, pp. 1525-1534, 2007.

[31] M. Mohiuddin, A. Zavabeti, F. Haque et al., "Synthesis of twodimensional hematite and iron phosphide for hydrogen evolution," Journal of Materials Chemistry A, vol. 8, no. 5, pp. 27892797, 2020.

[32] X. Zhang, S. Lin, Z. Chen et al., "Kaolinite supported nanoscale zerovalent iron for removal of $\mathrm{Pb}^{2+}$ from aqueous solution: reactivity, characterization and mechanism," Water Research, vol. 45, pp. 3481-3488, 2011.

[33] Z. Qin, H. Yin, X. Wang et al., "The preferential retention of ${ }^{\mathrm{VI}} \mathrm{Zn}$ over ${ }^{\mathrm{IV}} \mathrm{Zn}$ on birnessite during dissolution/desorption," Applied Clay Science, vol. 161, pp. 169-175, 2018.

[34] M. A. Tantawy, S. A. Ahmed, E. M. Abdalla, and M. I. Qassim, "Immobilization of copper ions laden kaolin waste: influence of thermal treatment on its immobilization in cement paste," Journal of Material Cycles and Waste Management, vol. 18, no. 2, pp. 263-272, 2016.

[35] L. Yan, T. Chan, and C. Jing, "Arsenic adsorption on hematite facets: spectroscopy and DFT study," Environmental Science: Nano, vol. 7, no. 12, pp. 3927-3939, 2020.

[36] X. Li and E. Bi, "The impacts of $\mathrm{Cu}(\mathrm{II})$ complexation on gatifloxacin adsorption onto goethite and hematite," Journal of Environmental Quality, vol. 49, no. 1, pp. 50-60, 2020.

[37] M. Sadowska, Z. Adamczyk, and M. Nattich-Rak, "Formation of hematite nanoparticle monolayers of controlled coverage and structure at polymeric microparticles," Journal of Colloid and Interface Science, vol. 505, pp. 509-518, 2017.

[38] J. Liu, X. Wu, Y. Hu, C. Dai, Q. Peng, and D. Liang, "Effects of $\mathrm{Cu}$ (II) on the Adsorption Behaviors of $\mathrm{Cr}$ (III) and $\mathrm{Cr}$ (VI) onto Kaolin," Journal of Chemistry, vol. 2016, Article ID 3069754, 11 pages, 2016.

[39] D. B. Singh, G. Prasad, and D. C. Rupainwar, "Adsorption technique for the treatment of As(V)-rich effluents," Colloids and Surfaces A: Physicochemical and Engineering Aspects, vol. 111, no. 1-2, pp. 49-56, 1996. 